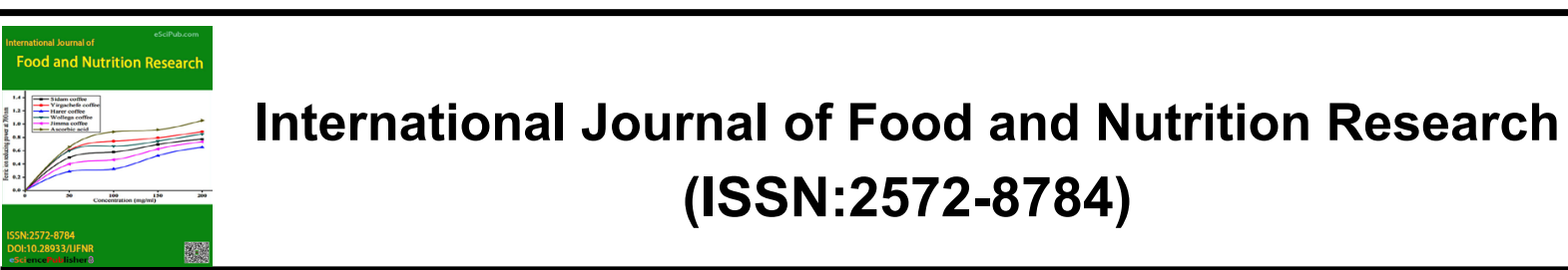

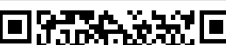

\title{
Food security in the time of Coronavirus (COVID-19). The Argentine
}

\section{case}

\section{Leda Giannuzzi}

Toxicology Laboratory, Exacts Sciences College, National University of La Plata (UNLP), La Plata, Buenos Aires. Centro de Investigación y Desarrollo en Criotecnología de Alimentos (CIDCA), CCTLa Plata. Facultad Ciencias Exactas, Universidad Nacional de La Plata. Street 47 and 116 (1900) La Plata, Argentina.

\section{ABSTRACT}

The context of pandemic of the human coronavirus COVID-19, preventive strategies based on mandatory social isolation (quarantine) were imposed by governments to reduce transmission in the community. However, they have had a strong impact on the economies of the countries and on the people as massive layoffs, decreased wages, uncertainty, inability to work formally, increasing precariousness and inequality and food insecurity. Without a doubt, the pandemic surprised Argentina without the necessary tools to amortize the attacks of the disease, and all the collateral consequences that emerge from it. The concept of food insecurity represents a situation or a process experienced by households in which there is a limited and uncertain availability of the quantity and quality of food that allow covering the nutritional requirements of people, thus as an also limited and uncertain availability of the ability to acquire them in an acceptable way from a social and cultural perspective. This work addresses household food insecurity at the micro-social level based on their own surveys and describes the strategies carried out by households in the metropolitan area of Buenos Aires city, Argentina to withstand the effect. FI status was assessed among 200 adult university students a mean age of $28 \pm 6$ years ( $57 \%$ female, $43 \%$ male) during isolation period in April -May 2020 using the food insecurity experience scale (FIES).

*Correspondence to Author:

Leda Giannuzzi

Toxicology Laboratory, Exacts Sciences College, National University of La Plata (UNLP), La Plata, Buenos Aires. Centro de Investigación y Desarrollo en Criotecnología de Alimentos (CIDCA), CCT-La Plata. Facultad Ciencias Exactas, Universidad Nacional de La Plata. Street 47 and 116 (1900) La Plata, Argentina.

How to cite this article:

Leda Giannuzzi. Food security in te time of Coronavirus (COVID-19). The Argentine case. International Journal of Food and Nutrition Research, 2020; 4:38.

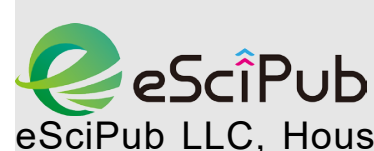

eSciPub LLC, Houston, TX USA. Website: https://escipub.com/ 
The students responded affirmatively and with a higher percentage value to the items related to the lack of money to consume healthy and nutritious food. Food security status of the 200 students survey, 23.5 per cent $(n=47)$ were food secure. Food insecurity was reported by $76.5 \%(n=153)$. Of these, $50 \%(n=100)$ were mild food insecurity, $25.5 \%(n=51)$ were moderate, while $1 \%(n=2)$ were severe food insecurity.

Food insecurity derived from access, as well as the difficulties of finding variety in food at affordable prices due to the obstacles imposed by the isolation affected food security. The changes on food intake during quarantine period was also analysed. In the current particular situation, it is advisable to improve the consumption of fresh food. Meat consumption has also been altered, shifting its consumption to cuts of less economic value. Among the reasons for this change in eating habits during this period, it is possible that the increase in stress, anxiety due to isolation, as well as the economic reasons and those that result from difficulties in accessing points of sale could explain these changes.

Keywords: Food security; COVID-19; FIES survey; Changes in food consumption; Argentina; Pandemic

\section{Introduction}

Argentina is a South American country that occupies the eighth position in the world by area $\left(2,780,000 \mathrm{~km}^{2}\right)$, it is the second largest country in Latin America. According to data from the Food and Agriculture Organization of the United Nations (FAO), Argentina ranks eighth among the countries with the largest arable land available, with 39.2 million hectares.

Argentina is ranked 17th in the world's fresh water availability and in a global space benefited by moderate temperatures without extreme limitations (hot or cold), which allow agricultural production with practically no restrictions.

Argentina has a population of $44,560,000$ people, with an extremely low population density of 16 inhabitants per $\mathrm{km}^{2}$ concentrated in a few large cities (Buenos Aires, Córdoba, Rosario and others). Most of the population is urban (agglomerations of more than 2000 inhabitants). The last census in 2010 indicated that $8.1 \%$ of the population is rural and $91.9 \%$ is urban. With a Gross Domestic Product (GDP) of approximately US $\$ 450$ billion, Argentina is one of the largest economies in Latin America [1].

This country is an exporter of beef, cereals (wheat and corn), oilseeds (sunflower and soybeans). It is the 1st world exporter of soybean oil, soybean meal, lemon concentrate, lemon esse- ntial oil, fish (Hubbsi hake), beans, yerba mate and peanut oil ${ }^{[2]}$. Occupies the 5th place in the ranking of beef producing countries with 3.12 billion tons according to USDA reports ${ }^{[3]}$. The Argentine population consumes an average of $51.4 \mathrm{Kg}$ beef / inhabitant per year ${ }^{[4]}$.

Argentina is in third place in the ranking of net food exports with US $\$ 32$ billion, preceded by Brazil with sales of US $\$ 76$ billion, and the Netherlands with US $\$ 33$ billion, according to data from the Institute of Economic Studies and International Negotiations with data from the World Trade Organization [1].

A country's net food exports result from deducting the value of food imports from the amount of total exports of these products. This indicator reflects the strategic potential to feed both its inhabitants and those of other countries and summarizes the country's contribution to global food security.

Food security is a situation that exists when all people, at all times, have physical, social and economic access to sufficient, safe and nutritious food that meets their dietary needs and food preferences for an active and healthy life ${ }^{[5]}$. Despite being a country with high food production, Argentina is going through a scenario of stagnation with inflation, external debt crisis and structural economic paralysis, to which must be 
added the strong validity of a division politicalideological about the problems facing society. For decades, it has been in a state of crisis aggravated by an unequal and structurally impoverished socioeconomic system that puts food security at risk.

Food security has four dimensions: availability, access, use and stability. These terms define how to ensure sufficient food supplies, the security of access to food for all consumers, the proper use and stability of production and prices [6]. These four pillars are described below and exemplified with reported statistical values for Argentina.

Availability, corresponds to the provision, supply or existence of food, that is, it deals with what is related to "supply", food production, productive infrastructure, inputs and agrifood chains. For Argentina in 2019, the composition (\%) of caloric availability by food groups were: cereals (33\%), meats $(18.8 \%)$, sugars $(14.8 \%)$, oils and fats $(14.1 \%)$, dairy products $(7.2 \%)$, fruits and vegetables $(4.6 \%)$, roots $(2.8 \%)$ and others $(6.3 \%)$. The average intake value was $3247 \mathrm{Kcal} /$ day / person. The indicators of the poverty rate for the urban area were $24.4(\%)$, the indigence rate 3.6 $\%$ and the average annual unemployment rate $10 \%{ }^{[7]}$.

Income poverty was $35 \%$ at the end of $2019{ }^{[8]}$. The interventions carried out by the state in order to promote availability are carried out through research services, technology transfer and agrifood quality that are provided by government agencies such as the National Institute of Agricultural Technology and the National Service of Agrifood Health and Quality.

Access is the way through which people can obtain food physically and economically, be it through barter, self-consumption, access to markets, increased disposable income through programs and instruments of social protection, food aid direct. An indicator that influences access to food is the price of the Basic Food Basket (BFB) which in Argentina during the year 2019 increased $58.1 \%{ }^{[8]}$. The BFB is the set of foods and beverages that satisfy nutritional, calorie and protein requirements, whose composition reflects the consumption habits of a reference population. It serves as an indicator of the indigence line and in November 2019 it was U\$S 73.5.

The Argentine currency began to depreciate in mid-2018 and, as of May 2020, it had lost more than $50 \%$ of its value against the US dollar compared to the same month of 2019.

The Argentine government has intervened in this regard through the Family Allowance Program for children and children with disabilities and laws such as the National Nutrition and Food Program within the framework of the National Food Security Law in force since 2003 that outlines the non-delegable duty of the State to guarantee the right to food of all citizens. The National Food Emergency Law, 2019 was also enacted with the aim of guaranteeing permanently and as a priority the right to food and food and nutritional security of the population ${ }^{[9]}$. Another contribution to access was through the Care Prices program, an initiative implemented since 2013, through a voluntary agreement between the State, manufacturers, distributors, supermarkets and wholesalers, which establishes reference prices for the most representative products of the BFB with the objective to contain price increases.

Biological use, is the influence of food quality on the nutritional condition of individuals and their health. This relates to hygiene, sanitation, food quality and safety, nutritional information, and how the body uses nutrients. This brings out the importance of non-food inputs in food security. Argentina registers in the total population over 18 years of age, overweight levels of $62.7 \%$ and Obesity (Body Mass Index (BMI) > 30) of $28.3 \%$ [10].

State interventions such as the Food and Nutrition Education Program provided by Law that promotes the development of permanent healthy habits for the production, selection, purchase, manipulation and biological use of food through nutritional food education have been carried out. Stability refers to the capacities to react to unfor- 
eseen events, political, economic, social crises and natural catastrophes that may change the conditions of the other dimensions, generating risk and vulnerability. In this dimension until 2019 , the frequency of natural disasters were storms (20\%), floods (15\%), droughts (10\%) and epidemics (3\%).

Food insecurity $(\mathrm{FI})$ is a situation or a process experienced by households that have a limited and uncertain availability of the quantity and quality of food that cover the nutritional requirements of people, as well as a limited and uncertain availability of the ability to acquire them in an acceptable way from a social and cultural perspective.

The most extreme expression of food insecurity is hunger. FAO defines hunger for consumption below $1800 \mathrm{Kcal}$ per day, a value required for most people to live a healthy and productive life. The term Global Hunger Index (GHI) has been defined as a tool designed to measure and track hunger globally and is calculated by the International Institute for Food Policy Research. For Argentina, the Global Hunger Index (GHI) in 2019 was 5.4 , which is considered low ${ }^{[11]}$.

The severity of food insecurity is measured using the Food Insecurity Experience Scale Survey Module (FIES-SM), consists of eight questions regarding people's access to adequate food, and can be easily integrated into various types of population surveys. The FIES methodology established by FAO constitutes a global measurement standard for FI [12]. The FIES-SM questions refer to the experiences of the individual respondent or of the respondent's household as a whole. The questions focus on self-reported food-related behaviour's and experiences associated with increasing difficulties in accessing food due to resource constraints.

In households, a first moment recognized as mild $\mathrm{Fl}$ occurs when there is concern of people about access to food, then strategies are adopted to adjust the family budget, affecting the quality and diversity of food in the diet.

A second moment or circumstance, identified as moderate $\mathrm{FI}$, occurs when adults in the home limit the quantity and quality of the food that only they consume.

A third moment, called severe $\mathrm{FI}$, is when the quantity and quality of food consumed by children is affected.

In Argentina, FI values in the total population was $20.2 \%$ in 2018 and $22.2 \%$ in 2019 (Argentine Social Debt Observatory of the Argentina Catholic University [13]. The increase in severe FI was manifested with greater emphasis in households in the Metropolitan Area, Buenos Aires (AMBA, a highly populated common urban area with 17 million inhabitants that include the City of Buenos Aires and 40 municipalities in the Province of Buenos Aires) with a value of $5.8 \%$ in 2019. Although the AMBA is the place where the hunger of vulnerable households grew the most, in cities such as Córdoba, Tucumán, Mendoza and Rosario there were also significant peaks of increase. Severe Fl impacted households where there are informal workers $(18.5 \%$ in 2018 increased to $20.5 \%$ in 2019) and the integrated worker, which increased from $8.5 \%$ to $9.5 \%$ in these period ${ }^{[13]}$. This is the result of the deterioration of the economy, the blow of inflation and the insufficiency of active social policies to attend to this situation.

In this situation picture Argentina faces the pandemic that led to a Preventive and Mandatory Social Isolation (PMSI) from March 20, 2020 that lasts until the end of September 2020. At the end of March 2020, the Government proposed a list of food products for mass consumption with prices based on emergency measures over a period of four months and allocated additional funds to maintain the operation of community kitchens. In addition, the coverage of social protection programs was expanded with the aim of benefiting more than 9 million people.

Different international publications have warned that the COVID-19 pandemic may have negative implications for population food security and long-term consequences ${ }^{[14]}$. The nutritional status of the most vulnerable population groups to deteriorate even more due to the socio-economic repercussions and health of COVID-19. 
The purpose of this study was to determine the prevalence of FI of Students University participating on line course in University of La Plata during the pandemic COVIC-19.

\section{Material and methods}

The FIES captures the access dimension of food security including aspects from monetary restraint and availability to dietary quality. The modified FIES was used to determine the severity of FI. The FIES-SM (Table 1) was provided in Spanish and was performed an online in April and May 2020.

Table 1: FIES survey adapted to the PMSI period and percentage of responses

\begin{tabular}{|c|c|c|c|}
\hline $\begin{array}{c}\text { During the PMSI, was there a time when, be- } \\
\text { cause of lack of money or other resources: }\end{array}$ & \multicolumn{3}{|c|}{ Percentage of people who answered } \\
\hline $\begin{array}{c}\text { You were worried you would not have enough } \\
\text { food to eat? }\end{array}$ & $\begin{array}{c}\text { It never hap- } \\
\text { pened } \\
(32 \%)\end{array}$ & $\begin{array}{c}\text { It happened } \\
\text { same times } \\
(49 \%)\end{array}$ & $\begin{array}{c}\text { It happened } \\
\text { several times } \\
(19 \%)\end{array}$ \\
\hline $\begin{array}{c}\text { You were unable to eat healthy and nutritious } \\
\text { food? }\end{array}$ & $\begin{array}{c}\text { Always (49\%) } \\
\text { It happened } \\
\text { same times } \\
(39 \%)\end{array}$ & $\begin{array}{c}\text { It happened } \\
\text { several times } \\
(12 \%)\end{array}$ \\
\hline You ate only a few kinds of foods? & $\begin{array}{c}\text { It never hap- } \\
\text { pened } \\
(32 \%)\end{array}$ & $\begin{array}{c}\text { It happened } \\
\text { same times } \\
(49 \%)\end{array}$ & $\begin{array}{c}\text { It happened } \\
\text { several times } \\
(19 \%)\end{array}$ \\
\hline You had to skip a meal? & No (76\%) & $\begin{array}{c}\text { It happened } \\
\text { sometimes } \\
(19 \%)\end{array}$ & $\begin{array}{c}\text { It happened } \\
\text { several times } \\
(5 \%)\end{array}$ \\
\hline You ate less than you thought you should? & \multicolumn{2}{|c|}{ No (85\%) } & Yes (15\%) \\
\hline Your household ran out of food? & \multicolumn{2}{|c|}{ No (92\%) } & Yes (8\%) \\
\hline You were hungry but did not eat? & \multicolumn{2}{|c|}{ No (95\%) } & Yes (3\%) \\
\hline You went without eating for a whole day? & \multicolumn{2}{|c|}{ No (97\%) } \\
\hline
\end{tabular}

Answer options included "yes, no, refused, don't know. The scale classifies respondents at different levels of severity: "food secure" (respondents who answer no to all questions) or "food Insecure" (respondents who experience a certain degree of food insecurity: mild, moderate and severe $\mathrm{FI})^{[14]}$.

The participants were 200 university students who attended the online Interdisciplinary Course (undergraduate) of Food Sovereignty of the $\mathrm{Na}$ tional University of La Plata, Buenos Aires, Argentina during the first four-month period 2020. Severity levels of FI were calculated based on their statistical guidelines and depended on the number of questions a participant answered affirmatively.

All of the $\mathrm{FI}$ scale questions were recoded into 2 categories ((often/sometimes vs. never) or (yes vs. no)). Each item was given a score of 1 if the answer pointed toward $\mathrm{FI}$, or 0 if it was in the food security direction.

The FI score range was from 0 to 8 . An additive total score was created and the persons were classified into 8 mutually exclusive levels of food (in) security using the following algorithms: i) Food Secure (score: 0); ii) mild FI (score: 1-3); iii) moderate FI (4-6) and iv) severe FI (7-8).

Data were analyzed using the Statistical Package (SPSS) IBM SPSS Statistics for Mac OS, Version 24.0 software. Descriptive statistics such as frequencies (percentages) and means \pm standard deviations were used in describing $\mathrm{FI}$ status. Comparison between genders was performed using student t-test. Cronbach's alpha coefficient was 0.849 (based on 200 participants), showing a very good internal reliability of the FIES ${ }^{[15]}$.

\section{Results and Discussion}


The students who answered the questionnaire were adult over the age of eighteen (28 \pm 6 , range between $20-35$ years old). Of these, 107 women (53.5\%) and 93 males (46.5\%) with high educational level and residence in the large urban centers of Buenos Aires, AMBA were registered. The percentage of responses to each item is presented in Table 1. It can be seen that the items related to the lack of money to consume healthy and nutritious foods and the need to reduce the variety of foods presented the highest percentages (Table 1). The students have access to the university with a medium and low socioeconomic level. It can be seen that FI derived from access, as well as the difficulties of finding variety in food at affordable prices due to the obstacles imposed by the PMSI for making purchases, affected FI.

Food security status of the 200 people survey, 23.5 per cent $(n=47)$ were food secure. FI was reported by $76.5 \%(n=153)$. Of these, $50 \%(n$ $=100)$ were mild $\mathrm{FI}, 25.5 \%(\mathrm{n}=51)$ were moderate $\mathrm{Fl}$ while $1 \%(\mathrm{n}=2)$ were severe $\mathrm{FI}$.
Gender differences were not detected $(p=0.701)$. More women informed moderate $\mathrm{FI}$ $(27.4 \%)$ in comparison with man (16\%) and the men were mayor mild $\mathrm{FI}(58.3 \%)$ than women $(45 \%)$.

The results indicated that the FI increased during the PMSI period. One possible reason was that the students did not have enough money to buy food and the mobility restrictions imposed by PMSI prevented them from doing informal jobs as well as traveling distances in search of lower prices and had to restrict the consumption and variety of food.

The recent report based on data from May, 2020 on en 500 households of AMBA, showed that the family income was reduced to half in $38 \%$ of household it was only partially compensated by social protection programs (13). The prevalence of household total FI (severe FI + moderate FI) has increased from $18.3 \%$ in 2019 to $19.9 \%$ in May 2020, and the prevalence of severe FI increased from $5.8 \%$ to $8.6 \%{ }^{[13]}$ (Table 2 ).

Table 2: Impact of COVID-19 on total FI and severe FI in a panel of 500 households residing in AMBA in May 2020 and their comparison with July-October 2019 in percentage of households (EDSA-UCA)

\begin{tabular}{|c|c|c|}
\hline Food insecurity & July -October 2019 & May 2020 \\
\hline Severe & 5.8 & 8.6 \\
\hline Moderate & 12.5 & 11.3 \\
\hline Total & 18.3 & 19.9 \\
\hline
\end{tabular}

The significant increase in severe $\mathrm{FI}$ focused on the most vulnerable sectors and affected those who lost their jobs or were unable to carry out work activities as a consequence of confinement policies.

During PMSI, an exploratory study carried out by Sudriá et al. 2020, ${ }^{[16]}$ on impact of the quarantine by COVID-19 on food habit practices in Argentina using an online questionnaire was performed. Was answered by 2,518 people, of whom 2201 corresponded to a population with omnivorous population (OP) and 317 to the population with vegetarian / vegan habits (VP) ${ }^{[16]}$. The demographic populations that answered the survey were mostly women under 50-year-old, of high educational level, with residence in the large urban of Buenos Aires, Córdoba and Santa $\mathrm{Fe}$. Increased stress, anxiety due to isolation, as well as the economic reasons and those that arise from the difficulties of accessing the points of sale are some of the hypotheses that explain the evident change in eating habits.

Responses were contrasted with dietary guidelines for the Argentine population prepared and updated by the Argentine Ministry of Health, $2016^{[17]}$

The habit of eating during the day has changed, the frequency of eating has increased. $80 \%$ of the respondents reported having affected their diet, eating more or disorderly. $55 \%$ of the OP and $62 \%$ of the VP say they consume food due to stress and anxiety. 
About the consumption of fruits, the majority of the Argentine population does not meet the recommended amounts (three per day) and during PMSI, 24\% of the respondents to the OP affirm that they have reduced the number and the majority assure that they eat between one and two. In relation to vegetables, the guidelines suggest eating two servings daily, however, during PMSI, $56 \%$ of this population did not cover them and $18 \%$ reduced their intake.

The decrease in the consumption of fruits and vegetables in this population was replaced by other foods such as potatoes, sweet potatoes and onions that provide few nutrients.

The ideal diet requires the intake of fresh fruit or vegetables, but the population, in compliance with the measures arranged, and decided to consume fewer servings. Furthermore, inflation in the prices of these products influenced consumer choice.

According to the Institute for the Promotion of Argentine Beef (IPCVA), ${ }^{[18]}$, the consumption of beef has not varied substantially during the PMSI (decrease of $2 \%$ ). The cut of minced meat for hamburgers and the cuts for stews grew $19 \%$. The barbecue has decreased by $43 \%$ due to the lack of social gatherings. Frozen hamburgers $(37 \%)$ and meat cuts for the oven (32\%) have also decreased. Regarding the consumption of meat products, there was an increase of $39 \%$ in the consumption of sausages and an increase of $8 \%$ in the consumption of "ultra-processed" foods. These products usually contain little or no whole food, they are industrial formulations mainly based on substances extracted or derived from food and additives [19, and 20].

With reference to dairy products, the recommendation is three servings a day, in its variants of milk, yogurt or cheese. In PMSI times, $74 \%$ of the OP does not satisfy this indication, but consumes between one and two. This population indicated that consume sweets regularly $(72 \%)$ and during PMSI increased their consumption $(10 \%)$. Soft drink consumption was $30 \%$ and increased $20 \%$ during this period. Regarding water consumption, $34 \%$ indicated that they ingest half or less than the recommended amount $(2 \mathrm{Li}-$ ters). A $54 \%$ of the OP increased the preparation of homemade meals, $44 \%$ preferred to maintain a regular diet and $2 \%$ increased the delivery service. However, they do not include fruits, vegetables, cereals and legumes and tend to prepare farinaceous foods such as breads, cakes, sweets, puddings, biscuits. This population presented a body weight corresponding to the overweight category with BMI average value of 25.5 $\mathrm{kg} / \mathrm{m}^{2}{ }^{[21]}$. If these trends continue, in the shortmedium term, there could be greater overweight. Vegan Population (VP) in Argentina corresponds to $9 \%$ of the total population (four million people) according to a survey conducted by the Argentine Vegan Union. This population depends on their purchase in dietetics, fairs and micro-enterprises suspended during PMSI. A 63 $\%$ of the VP consumes 3 or more daily servings of vegetables while $12 \%$ reduced it. Regarding fruits, $27 \%$ consume two or three servings daily and $23 \%$ indicated an increase in consumption. In relation to baked goods and cereals (cookies, flours) the percentages tended to increase. This population usually consumes few soft drinks and sugary drinks but in PMSI it has increased $20 \%$, similar to alcohol that increased $15 \%$. Water consumption did not reach the recommended values and $18 \%$ decreased its consumption.

Their usual diet includes legumes, seeds, nuts and whole grains, registering an increase in these foods, except for seeds and nuts, which tended to decrease. The feeding of the VP must be supplemented with vitamin B12, being this essential nutrient for the nervous system since it is not found in foods of plant origin, occurring in reduced amounts in dairy and eggs, however 57 $\%$ of the VP indicated taking supplements and only $74 \%$ were able to do it. A $50 \%$ of the VP indicated that they consumed homemade meals, $48 \%$ maintained their usual diet and $2 \%$ increased the delivery service. Regarding body weight, $67 \%$ of the VP had a healthy BMI with an average value of $22.9 \mathrm{~kg} / \mathrm{m}^{2}$.

In order to know the variation in alcohol intake before and during PMSI, an online survey with 50 
00 the individual respondent living in the Province and the City of Buenos Aires was performed [22]. It was found that the number of people who consume alcoholic beverages tripled every day. The number is accentuated in the group of 35 to 44 years, among whom it almost quadrupled (from $4.6 \%$ to $18.1 \%$ ). Among those aged 18 to 24 , this percentage also quadrupled (from 5.2\% to $20.7 \%$ ). Alcohol consumption was incorporated into new situations of daily life: about $20 \%$ started drinking during dinner and $15 \%$ while reading or listening to music or watching television. People who prefer to drink wine, $40 \%$ of these people increased the amount of glasses, and those who drink beer increased consumption by $25 \%$. The percentage of those who drank only on weekends was reduced by half. The repetition of one day after another in isolation translates into an in-differentiation between days of work or rest and, thus, also with regard to drinking alcohol.

Among the reasons for drinking more alcohol, those that cause a disorganization of time prevail. $42.2 \%$ said they drink because they have more free time and $29.4 \%$ because of the lack of a stable routine. A $33.6 \%$ of people indicated that the emotional involvement caused by PMSI was the cause. However, respondents agree that the triggering cause of drinking more is in uncertainty, both economically and not knowing when this situation ends. Alcohol consumption was perceived as non-problematic by 9 out of 10 (it does not affect health, their ties or at work). On the other hand, the number of people who do not drink alcohol doubled (from $8.5 \%$ to $15.95 \%$ during PMSI) due to the lack of outings or social events (70\%).

The World Food Program has warned of the possibility of doubling FI in low- and middle-income countries due to loss of income and remittances ${ }^{[23]}$.

In Argentina, the PMSI policy in the context of a pandemic generated large-scale changes in a labour scenario that had deteriorated for decades. Despite the existence of a careful pricing policy, an increase of $3.01 \%$ in the Basic Food Basket was registered ${ }^{[24]}$. These factors are key to the evaluation of $\mathrm{Fl}$.

Some of the consequences of $\mathrm{Fl}$ include but are not limited to poor health, as well as decreased cognitive performance and academic achievement. The quality of the diet is a fundamental factor for the state of health of the people.

There is a shift from the traditional eating pattern based on fresh or minimally processed foods, prepared at home, towards an abundant diet in "ultra-processed". In Argentina, the average growth of per capita retail sales of these foods during 2009-2014 was 9\%. The 10 most important products are: Cookies (biscuits), Soft drinks, Caramels (sweets), Yogurt sweetened with flavourings, Cakes, cakes and desserts, Industrial breads, Sauces and dressings, Juices and sweetened beverages, Sweet and savory snacks, Dairy drinks with flavourings [25].

The high consumption rate of diets high in saturated fat, sugars and refined carbohydrates worldwide, contributes to the prevalence of obesity and type 2 diabetes, and could place these populations at a higher risk of developing COVID-19 in a pathology severe with mortality. Obesity has been associated with disease severity among patients with coronavirus disease. Obesity is closely related to Diabetes Mellitus, hypertension, and cardiovascular disease, the aforementioned risk factors for severe COVID19 [26, 27, 28]. Physical inactivity, common in obesity, can lead to an impaired immune response [29]. A database review of 4285 scientific articles studied the value of $\mathrm{BMI}$ as a tool to assess the risk of development and / or aggravation of this disease. The mean BMI value of severe COVID19 patients ranged from 24.5 to $33.4 \mathrm{~kg} / \mathrm{m}^{2}$, ver-

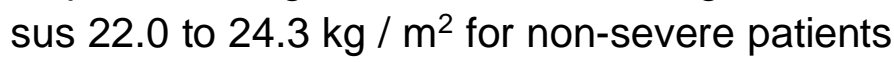
was informed. The use of BMI is important during this pandemic, as it should be applied to nutritional support therapy during hospitalization of infected patients, as well as being considered in the home confinement population [30]. The COVID-19 pandemic intensifies the causes of 
vulnerability and deficiencies in global food systems, understood as all activities and processes that affect food production, distribution and consumption.

Governments must incorporate nutrition in their approaches to agriculture and promote healthy habits with programs in this regard to minimize the impact of the pandemic on people

\section{Declaration}

Ethical Approval and Consent to participate. The review was prearranged and freedom from requiring ethical support from University of $\mathrm{La}$ Plata, School of Exacts Sciences

\section{References}

[1] World Bank (2020)

https://www.worldbank.org/en/country/argentina/overview

[2] Ministry of Agro-industries, Ministry of Production (2017) Alimentos Argentinos

[3] United State Department of Agriculture. Definitions of Food Security. Available online at: https://www.ers.usda.gov/topics/food-nutritionassistance/food-security-in-the-us/definitionsof-food-security.aspx

[4] IPCVA). IPCVA El Instituto de Promoción de la Carne Vacuna Argentina. (2019)

http://www.ipcva.com.ar/estadisticas/vista_consumos_promedio.php

[5] FAO (Food and Agricultural Organization), 2002. The State of Food Insecurity in the World 2001. Rome.

[6] FAO (Food and Agricultural Organization), 1996. El Programa Especial para la Seguridad Alimentaria. Roma: FAO.

[7] ECLAC. Economic Commissions for LatinAmerican and the Caribbean's, 2018.

[8] INDEC. The National Statistics Institute INDEC (2019).

[9] National Food Emergency Law (2019) National Food Emergency, Law 27519, https://www.boletinoficial.gob.ar/detalleAviso/primera/217588/20190930.

[10] CELAC, 2016, http://celacinternational.org/celac-4/

[11] Global Hungry Index, 2019. https://www.globalhungerindex.org/argentina.html

[12] Ballard, T. J., Kepple, AW., Cafiero, C. The Food Insecurity Experience Scale: Development of a Global Standard for Monitoring Hunger Worldwide. 2013. FAO, Rome.

[13] EDSA UCA. Observatory-of-Social-Debt-Argentina/statistics-edsa http://uca.edu.ar/es/observatorio-de-la-deudasocial-argentina/estadisticas-edsa

[14] FAO/WHO. The State of Food Security and Nutrition in the World 2020. Transforming food systems to promote affordable and healthy diets. Roma, 2020, https://doi.org/10.4060/ca9699es

[15] Frongillo, EA. (1999) Validation of measures of food insecurity and hunger. J. Nutr. 129: 506S509 s.

[16] Sudriá, ME., Andreatta MM., Defagó, MD, 2020. Los efectos de la cuarentena por coronavirus (covid-19) en los hábitos alimen- tarios en Argentina DIAETA; N 38, 10 - 19.

[17] Ministerio de Salud de la Nación. Guías Alimentarias para la Población Argentina, Buenos Aires. 2016.

http://www.msal.gob.ar/images/stories/bes/graficos/0000000817cnt-2016-04_Guia_Alimentaria_completa_web.pdf

[18] IPCVA. El Instituto de Promoción de la Carne Vacuna Argentina (2019)

http://www.ipcva.com.ar/estadisticas/vista_consumos_promedio.php

[19] Martinez Steele E., Baraldi LG, Louzada ML, Moubarac J-C, Mozaffarian D, Monteiro CA. UItra-processed foods and added sugars in the US diet: evidence from a nationally representative cross-sectional study. BMJ Open, 2016, 6(3), e009892. doi:10.1136/bmjopen-2015-009892

[20] Moubarac J-C, Batal M, Louzada ML, Martinez SE, Monteiro CA et al. Consumption of ultra-processed foods predicts diet quality in Canada. Appetite (2016) 108:512-520. doi: 10.1016/j.appet.2016.11.006

[21] World Health Organization. Prevalence of obesity among adults, BMI $\geq 30$, age-standardized Estimates by WHO region. (1990) https://apps.who.int/gho/data/node.main.A900A ?lang=en

[22] Jones D., Camarotti, A.C. Consumo de alcohol en cuarentena por COVID-19. Encuesta en el área Metropolitana de Buenos Aires, (mayo 2020). Instituto de Investigaciones Gino Germani, Facultad de Ciencias Sociales, UBA. http://areasalud.sociales.uba.ar/estudio-consumo-de-alcohol-durante-cuarentena/

[23] Global Report on Food Crises. Joint analysis for better decisions Food Security Information Network, 2020.

https://www.wfp.org/publications/2020-globalreport-food-crises?_ga=2.210919445.108192446.159444058 $1-1560281456.1594440581$

[24] INDEC. The National Statistics Institute. Dirección de Índices de Precios de Consumo. Valorización mensual de la canasta básica alimentaria 
y de la canasta básica total. Gran Buenos Aires, 2020, 4: 106.

[25] OPS Pan American Health. Organization Food and Agriculture Organization of the United Nations 1996. The Special Program for Food Security. 2019. Roma: FAO.

[26] Garg S, Kim L, Whitaker M, et al. Hospitalization Rates and Characteristics of Patients Hospitalized with Laboratory-Confirmed Coronavirus Disease 2019 - COVID-NET, 14 States, March 1-30, 2020. MMWR Morb Mortal Wkly Rep (2020) 69:458-464.

doi.org/10.15585/mmwr.mm6915e3external icon.

[27] Orioli L, Hermans MP, Thissena JP, Maiter D, Vandeleenea B, Yombi J-C. COVID-19 in diabetic patients: Related risks and specifics of management COVID-19. Annales d'Endocrinologie (2020) 81: 2-3, 101-109.

[28] Simonnet A, Chetboun M, Poissy J, et al. High Prevalence of Obesity in Severe Acute Respiratory Syndrome Coronavirus-2 (SARS-CoV-2) Requiring Invasive Mechanical Ventilation. Obesity (2020) 28: 1195 - 1199.

[29] Damiot A, Pinto A, Turner JE, Gualano B. Immunological Implications of Physical Inactivity among Older Adults during the COVID-19 Pandemic. Gerontology (2020) DOI: 10.1159/00 0509216

[30] Soriano JM, González A, Soler C, Catalá-Gregori Al, Merino-Torres JF. Body Mass Index (BMI) and Coronavirus Disease 2019 (COVID19): A Living Systematic Review. Preprints. 2020, doi: 10.20944 / preprints202005.0166. v1. 